medical staff at St. Boniface General Hospital in Winnipeg, has urged the Society of Obstetricians and Gynaecologists of Canada to weigh in on the issue.

"In my view, collection of personal information in this context is abhorrent and reprehensible," Hall, who is also a professor at the University of Manitoba, wrote Dec. I3 to the SOGC executive.

"If the pharmacists don't need it for a bottle of aspirin, they don't need it for Plan B either," he later told CMAJ, referring to the collection of identifying information.

Dr. André Lalonde, SOGC executive vice-president, says the Society just wants to move the issue forward. "We're not interested in battles, we're just interested in getting these drugs to women as best we can."

Cavoukian and Loukidelis both say they are worried about the security of the data once pharmacists collect and store it, and about whether individual pharmacists had policies letting women know what they used the information for and what would ultimately happen to that data.

Cavoukian has already had a call from one woman who had a "distressing" experience when she went to obtain levonorgestrel from a pharmacist within the last 2 weeks, before the new guidelines took effect.

"She was humiliated. She was asked these very embarrassing questions and she didn't understand why," Cavoukian said in an interview.

The woman thanked Cavoukian for her intervention, and Cavoukian in turn saluted the Ontario pharmacists. "They were wonderful and I was delighted with the cooperation and the spirit with which they met us."

The Canadian Women's Health Network is also pleased by the Ontario pharmacists decision. Chair Abby Lippman says "We hope pharmacists in other provinces follow suit, and that all other processes that impede or delay access to women and girls will be lifted." - Laura Eggertson, CMAJ, with notes from Andréa Ventimiglia.

\section{HTLV-1 virus detected in}

\section{Nunavut}

$\mathrm{N}$ unavut health officials report at least one death related to human T-cell lymphotropic virus type I (HTLV-I) and "fewer than 20 " infected persons.

Nunavut's Medical Officer of Health, Dr. Issac Sobol, says residents need to take this very seriously, but adds, "It's not what we consider an outbreak. In fact, it's been here a number of years." It can take up to 20 years before symptoms appear. There is no effective treatment to reduce the viral load.

In response to the death and reported cases, the Nunavut Department of Health and Social Services began offering testing for HTLV-I to pregnant women and the population in general in October, "We worried about our capacity to handle demand [from the general population]," says Sobol. As of Dec. 7, only 300 people had been tested.

Sobol would not disclose the precise number of people infected or the number of HTLV-I-related deaths. He stated that such caution is common in sparsely populated areas where anonymity is difficult. It is important to "ensure that Nunavummiut feel absolutely confident that no information will ever be revealed that could in any way be traced back to either communities or to individuals." Even one death in a small community could raise suspicions.

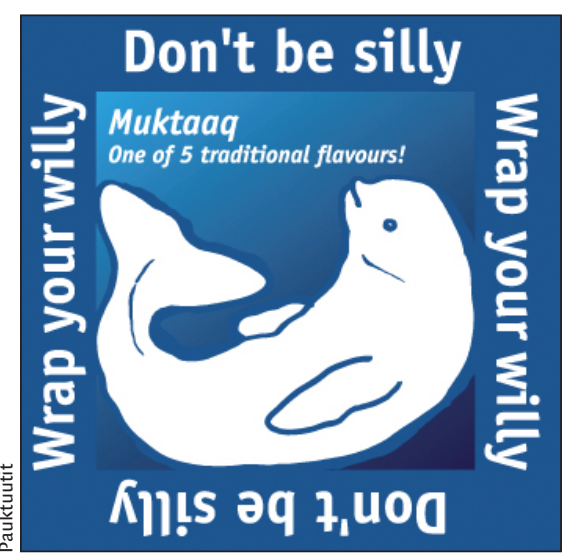

Custom condom wrappers, community events, posters and other strategies help prevent the spread of STDs, including HTLV-1, in Nunavut.
Box 1: HTLV-1 revealed

Human T-cell lymphotropic virus type 1 (HTLV-1) is a retrovirus endemic in Japan, West Africa, the Caribbean, South America and Melanesia. It has also been reported in other areas such as North America and Europe, where about 1\% of the population are carriers; in Japan between $6 \%$ and $37 \%$ of the population are infected. After a long asymptomatic phase, $2 \%-5 \%$ of people infected with HTLV-1 go on to develop adult T-cell leukemia; a smaller proportion of infections (0.1\%-2\%) result in HTLV-1 associated myelopathy, a progressive neurological disease. The 2 most common ways of getting the virus are through blood contact (e.g., blood products, intravenous drug use) and mother-to-child transmission through breast milk. There are about 20 million infected people worldwide.

HTLV-I is rare in Canada (see Box I), but the number of cases is not known because it's not a reportable disease in most jurisdictions. Canadian Blood Services has been screening donated blood for HTLV-I since 1990 and reports an average of IO-I2 positive tests per 800 ooo donations annually (prevalence of $0.0014 \%$ ). If even I5 people in Nunavut are infected, among a population of 29000 , the prevalence is $0.05 \%$.

HTLV-I can be transmitted sexually, which is cause for concern. "We know that there are still high levels of unprotected sex occurring because of our static chlamydia rates," says Dr. Geraldine Osborne, Nunavut's associate chief medical officer of health. Chlamydia rates have remained fairly stable since I99I at 2500 per 100 ooo population, compared to 188 per 100 ooo in Canada generally. Gonorrhea rates have declined from 900 per 100000 in I99I to 250 today, largely due to "effective treatment and contact tracing," says Osborne. Rates for other STIs including syphylis and HIV are very low; less than 20 reported cases each.

HTLV-I will top the agenda at a sexual health symposium at the end of February, says Aideen Reynolds, manager of Sexual Health Policy and Program for 
Pauktuutit, an Ottawa-based NGO that has offered STI prevention programs for the North since 1999 .

Reynolds says the problems are myriad: "How do you mobilize communities to take it on and believe that they are at risk?"

Part of the solution involves proving risk. The Nunavut department of health and the Public Health Agency of Canada (PHAC) are developing a seroprevalence study that includes anonymous testing of all blood samples taken in the territory. Preliminary results are expected by June; statistically significant results will take 2 years.

Dr. Frank Plummer, director general of PHAC's Centre for Infectious Disease Prevention and Control says HTLV-I is "not a huge public health threat." The important thing is to ensure there is antenatal screening in areas where there is an appreciable prevalence, he adds. Barbara Sibbald, CMAJ

DOI:I0.1503/cmaj.05158I

\section{News@a glance}

Mental health: The new Canadian Mental Health Commission will promote public education, coordinate fragmented policies and programs and see to it that best practices are shared across Canada. Working at arm's-length from government, the organization has a ro-year mandate. Its 19 -member board will be appointed this summer. One in 5 Canadians experiences a significant mental health episode during their lifetime.

Nobel goal: One of the co-winners of the 2005 Nobel Peace Prize is using its share of the award, about $\$ 750$ ooo, to fund training in cancer management and childhood nutrition in developing countries. The prize was awarded to the International Atomic Energy Agency (IAEA) and its Director General, Dr. Mohamed ElBaradei, "for their efforts to prevent nuclear energy from being used for military purposes and to ensure that nuclear energy for peaceful purposes is used in the safest possible way." The Austria-based agency is set- ting up the IAEA Nobel Cancer and Nutrition Fund, which will pay for fellowships and training courses in regional centres in Africa, Asia and Latin America. - Debra Martens, Vienna, Austria

Saskatoon switch: A student-managed health clinic is offering primary holistic health care to people in Saskatoon's west side. The Student Wellness Initiative Toward Community Health (SWITCH) employs medical and health care students from the Universities of Saskatchewan and Regina and the Saskatchewan Institute of Applied Science and Technology. It benefits the community and "provides an interdisciplinary service learning opportunity in a creative and unique environment," says SWITCH coordinator Carole Courtney. - Kristen Everson, Ottawa

Cancer vaccine in India: This spring, the Indian government plans to introduce a low-priced and efficacious vaccine to control cervical cancer, a disease that kills about 74 ooo women annually in India. More than 130000 new cases - about $25 \%$ of the global total - are reported in India annually. India has no organized screening program and many Indian women - particularly the $75 \%$

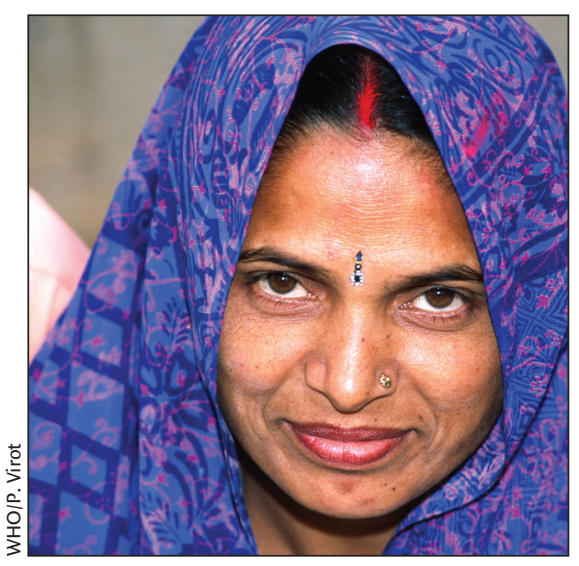

who live in rural areas - lack both awareness of the disease and access to prevention and treatment facilities. The incidence of late disease is $3 \%$ to $4 \%$ in British Columbia; in India it is about $73 \%$. Trials of the vaccine in India are expected to be complete this spring, after which the government expects to make the vaccine available, says Health Minister Anbumani Ramadoss. The In- dian Council of Medical Research is negotiating an affordable supply of the vaccine with Merck, Ramadoss added. — Sanjit Bagchi, Kolkata, India

Green goals: Canadian premiers and municipal leaders from the US, Europe, and Australia have signed a declaration to combat global warming and promised to meet or exceed the original Kyoto Protocol targets of reducing greenhouse gas emissions by $20 \%$ by 2010 . During the UN Climate Change Conference in Montreal, Dec. 6, Igo elected officials at municipal, state and provincial levels agreed to aim for a reduction of $30 \%$ by 2020. To date, 157 countries have ratified the Protocol; conference attendees tried to persuade others, notably Australia and the US, to sign on. - Andréa Ventimiglia, Ottawa

HIV stats: An estimated 40.3 million people now have the AIDS virus, up from 37.5 million in 2003 , reports the WHO and Joint UN Programme on HIV/AIDS in AIDS Epidemic Update 2005. More than 3 million people, included 500000 children, died of AIDSrelated illnesses in 2005. The steepest increases in HIV infections occurred in Eastern Europe and Central Asia (25\% increase to r.6 million) and East Asia. China reports 840 ooo HIV/AIDS cases among its $\mathrm{I} .3$ billion citizens. Up to Io million Chinese could carry the HIV virus within 5 years, unless preventive measures are stepped up, says Dai Zhicheng, director of the Health Ministry's Committee of AIDS Experts. WHO has echoed his concern. There has, however been progress in some countries. Kenya, Zimbabwe and some Caribbean countries all have slight declines in HIV prevalence over the past few years. In Kenya, adult infection rates have decreased from 10\% in the late 1990 s to $7 \%$ in 2003.

Research ethics: The Canadian Institutes of Health Research Ethics Office has published its Best Practices for Protecting Privacy in Health Research (www.cihr-irsc.gc.ca/e/29138.html) as a resource and guide for researchers. — Compiled by Barbara Sibbald, CMAJ

DOI:Io.I503/cmaj.051583 